\title{
EDUCATIONAL ABSTRACTS
}

Abstracted by Dorthea Juul, Ph.D.

169 Change without reform: the case of Stanford University School of Medicine, 1908-1990

169 Emerging criteria for quality in qualitative and interpretive research

170 Types of errors in synthesizing research in education

170 Confronting counsels of despair for the behavioral sciences

\section{EDUCATIONAL COMPUTING}

172 Software Reviews: American Psychiatric Press's "American Psychiatric Electronic Library" and Gold Standard Multimedia's "Clinical Pharmacology" Thomas A. M. Kramer, M.D., Robert S. Kennedy, M.A.

\section{Correction Notice}

In the Summer 1997 issue of Academic Psychiatry (Volume 21, No. 2), the last name of one of the co-authors of the article "The Art and Angst of the Mentoring Relationship" (pages 61-71) was misspelled. The second co-author's name is Marc S. Litle, M.D., not Little, which was printed in the issue. Our sincere apologies to Dr. Litle, and we regret the error.

-The Editors 